\title{
A Familial Case Study Exploring Craniofacial, Velopharyngeal, and Speech Variations in Pierre Robin Sequence
}

\author{
Katelyn J. Kotlarek', Jaclyn R. Kotlarek², Pamela J. Reitnauer ${ }^{3}$, Jamie L. Perry \\ ${ }^{1}$ Department of Communication Sciences and Disorders, East Carolina University, Greenville, NC; ${ }^{2}$ Department of Pediatrics, Division of Medical \\ Genetics, University of lowa Hospitals and Clinics, lowa City, IA; ${ }^{3}$ Genetic Counseling Training Program, Cone Health System, University of North \\ Carolina-Chapel Hill, University of North Carolina-Greensboro, Greensboro, NC, USA
}

A descriptive, prospective case study design was used to describe craniofacial, velopharyngeal, and speech measures of three siblings with a family history of Stickler syndrome. Two of the siblings had Pierre Robin sequence and cleft palate. All participants underwent nasometry, perceptual resonance rating, speech sound analysis, and magnetic resonance imaging. The child with a history of compensatory articulation errors showed notable differences in velopharyngeal function and medical history, as well as craniofacial and velopharyngeal dimensions when compared to siblings without a history of these speech errors. Further analysis of velopharyngeal and speech measures should be performed using a larger sample size within this population.

Keywords: Pierre Robin sequence, MRI, Speech, Velopharyngeal, Craniofacial

\section{INTRODUCTION}

Pierre Robin sequence (PRS) describes a pattern of features present in an individual initially caused by underdevelopment of the mandible in utero [1]. This can lead to other features such as glossoptosis, cleft palate, feeding and breathing difficulties, and failure to thrive [2]. The incidence reported varies from 1:8,500 to 1:14,000 live births [3]. PRS may occur in isolation, but it is part of an underlying disorder or syndrome in approximately $50 \%$ of cases [4]. It is most commonly associated with Stickler syndrome [5], being diagnosed in 18-35\% of individuals with PRS [4,6,7].

Stickler syndrome is a connective tissue disorder that can be associated with distinctive craniofacial features, eye problems, hearing impairment, mitral valve prolapse, and various skeletal and joint findings $[4,8]$. However, Stickler syndrome demonstrates wide variability in features leading to delayed or missed diagnoses in milder cases, even among individuals in the same family [8-10]. Despite variable expressivity, Stickler syndrome is completely penetrant. Three types of Stickler syndrome have been described based on collections of represented features. A diagnosis of Stickler syndrome is made clinically. Consensus has not been achieved on diagnostic criteria. However, non-validated criteria have been established for type 1 Stickler syndrome, which includes the presence of features, family history, and known pathogenic variants in autosomal

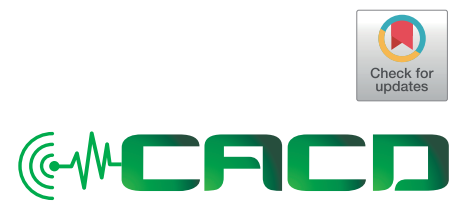

Received: June 14, 2018

Revision: September 27, 2018

Accepted: December 18, 2018

Correspondence:

Katelyn J. Kotlarek

epartment of Communication Sciences and Disorders, 2310A Health Sciences Building, East Carolina University, Greenville, NC, USA

Tel: +12527446110

Fax: +12527446109

E-mail:kotlarekk15@students.ecu.edu

American Cleft Palate-Craniofacial Association 75th Annual Meeting Pittsburg, PA

April 11, 2018

American Speech-Language-Hearing Association Convention

Los Angeles, CA

November 10, 2017

C 2018 The Korean Association of SpeechLanguage Pathologists

This is an Open Access article distributed under the terms of the Creative Commons Attribution NonCommercial License (http://creativecommons.org/ licenses/by-nc/4.0/) which permits unrestricted noncommercial use, distribution, and reproduction in any medium, provided the original work is properly cited. 
dominant genes [11].

Magnetic resonance imaging (MRI) is the only imaging modality that allows visualization of the internal musculature in vivo. MRI has been successfully used to describe craniofacial, velopharyngeal, and levator veli palatini (levator) measures in children. Studies have previously examined the levator muscle in children with noncleft and cleft palate anatomy [12-14]. These MRI studies demonstrate the value of using MRI for assessing velopharyngeal structures and their function and the potential clinical utility of MRI in improving postsurgical speech outcomes. However, to the best of our knowledge, no studies have described the use of MRI to characterize velopharyngeal muscular structures in individuals with PRS [16]. Structural and functional investigations among this population have been isolated to radiographic and computer tomography studies [16-25]. A greater understanding of the anatomy would provide important insight into speech outcomes and variations among those with PRS and accompanying syndromes related to velopharyngeal closure and speech.

In this case study, we describe the speech and craniofacial anatomy of three siblings with a familial history of Sticker syndrome, two of which were diagnosed PRS and cleft palate (status post cleft palate repair). The purpose of this study is to explore potential anatomical predictors for speech outcomes, given that one child developed compensatory articulation errors and hypernasality despite similar upbringing and diagnoses. Relative implications contribute to further discussion on speech and surgical outcomes in children with PRS, particularly with a family history of Stickler syndrome.

\section{CASE REPORTS}

\section{Methodology}

In accordance with the local Institutional Review Board, three English-speaking, Caucasian siblings were recruited to participate in this study. A self-reported family history was obtained. A comprehensive speech evaluation was conducted for all participants, which included completion of the Americleft protocol speech sample [26], perceptual resonance rating, Simplified Nasometric Assessment Procedures-Revised (SNAP-R) [27], and pressure-flow analysis. The Americleft protocol speech sample was used to assess articulation and consists of the American English sentence sample (repeated sentences), rote counting, and a two-minute conversation sample [26]. Perceptual resonance ratings for hypernasality and hyponasality were made on a 5-point and 3-point scale, respectively, which is consistent with the Americleft Speech Project protocol [26].

A Phillips 1.5 Tesla MRI scanner (Eindhoven, The Netherlands) and head coil were used to scan participants while lying in the supine position. The imaging protocol is consistent with that used in previous MRI investigations of the velopharyngeal muscles [28]. An elastic strap attached to the head coil was used to stabilize the head during the scan to reduce motion artifact that negatively influence image quality. Participants were instructed to breathe through their nose, and images were collected at rest with the velum in a fully-lowered position, resting on the tongue base.

Image processing methods were consistent with previously reported MRI investigations [28-30]. Raw magnetic resonance images were transferred into Thermo Scientific ${ }^{\mathrm{TM}}$ Amira $^{\mathrm{TM}}$ Software (Thermo Fisher Scientific, Waltham, MA, USA), which includes a native Digital Imaging and Communications in Medicine support program to ensure that anatomical geometry is maintained. Craniofacial and velopharyngeal measures were taken from the midsagittal image. Levator dimensions were taken from the oblique coronal image, which is a coronal image rotated to allow viewing of the levator muscle in its entirety. The measures selected in the present study reflect measures commonly reported in the literature [30-35] and velopharyngeal analyses using MRI [30,36-39]. Measures are defined in Table 1. Craniofacial landmarks and levator muscle locations were identified manually.

\section{Reliability}

Pearson product moment correlation was used to obtain inter- and intra-rater reliability measures. A perceptual resonance evaluation was completed on all three participants by two speech-language pathologists with experience in cleft palate speech evaluation. Inter-and intra-rater reliability for perceptual resonance measures were excellent ( $r=1.00$ for both). Reliability was completed on one-third of all MRI measurements. Inter-and intra-rater reliability ranged between $r=0.96$ to $r=0.99$. Intra-rater reliability was calculated using separate measurements completed by two researchers with experience in 3D MRI data analyses.

\section{Family history}

The family history is shown in the subsequent pedigree (Figure 1), which was created using the Proband application for iPad (Children's Hospital of Philadelphia Department of Biomedical and Health Informatics, Philadelphia, PA). Individu- 
Table 1. Descriptions of craniofacial and velopharyngeal variables of interest

\begin{tabular}{|c|c|}
\hline \multicolumn{2}{|l|}{ Craniofacial variables } \\
\hline Nasion-sella turcica & Linear distance $(\mathrm{mm})$ from nasion to sella turcica as seen on a midsagittal image \\
\hline Sella turcica-basion & Linear distance $(\mathrm{mm})$ from sella turcica to basion as seen on the midsagittal image \\
\hline Opithsion-basion & Linear distance $(\mathrm{mm})$ from opithsion to basion as seen on the midsagittal image \\
\hline NSB angle & $\begin{array}{l}\text { Inner angle (degrees) created between the intersection of the nasion-sella turcica and sella turcica-basion reference lines as } \\
\text { seen on the midsagittal image }\end{array}$ \\
\hline SBO angle & $\begin{array}{l}\text { Inner angle (degrees) created between the intersection of the sella turcica-basion and opithsion-basion reference lines as } \\
\text { seen on the midsagittal image }\end{array}$ \\
\hline SN-Point B angle & $\begin{array}{l}\text { Angle (degrees) created at the innermost curvature from the anterior nasal spine to the crest of the maxillary alveolar } \\
\text { process with sella turcica-nasion as a reference line as seen on the midsagittal image }\end{array}$ \\
\hline SN-Point A angle & $\begin{array}{l}\text { Angle (degrees) created at the innermost curvature from chin to the alveolar process of the mandible with sella turcica- } \\
\text { nasion as a reference line as seen on the midsagittal image }\end{array}$ \\
\hline Point A-N-Point B angle & Angle (degrees) of maxilla relative to mandible as seen on the midsagittal image \\
\hline ANS-basion & Linear distance $(\mathrm{mm})$ from anterior nasal spine to basion as seen on the midsagittal image \\
\hline Facial height & Linear distance $(\mathrm{mm})$ from nasion to menton as seen on as seen on the midsagittal image \\
\hline Cranial length & Linear distance $(\mathrm{mm})$ from front of head to back of head as seen on an axial image \\
\hline Cranial width & Linear distance $(\mathrm{mm})$ from left of head to right of head at widest point as seen on an axial image \\
\hline Cranial index & Cranial width divided by cranial length, multiplied by 100 \\
\hline \multicolumn{2}{|c|}{ Velopharyngeal variables } \\
\hline Origin to origin & $\begin{array}{l}\text { Linear distance }(\mathrm{mm}) \text { between the two points of origin for the right and left levator muscle bundles as seen on an oblique } \\
\text { coronal image }\end{array}$ \\
\hline Levator length & $\begin{array}{l}\text { Distance (mm) of the levator veli palatini muscle from the base of the skull (origin) through the midline of the muscle bundle } \\
\text { as seen on an oblique coronal image. The right and left muscle bundles were measured and calculated as a mean value }\end{array}$ \\
\hline Angle of origin & $\begin{array}{l}\text { Angle (degrees) created by the line connecting the two temporal origins of the levator muscle and the line coursing through } \\
\text { the levator muscle bundles as seen on an oblique coronal image. Right and left measurements were averaged for a mean } \\
\text { value }\end{array}$ \\
\hline Extravelar length & $\begin{array}{l}\text { Distance }(\mathrm{mm}) \text { of the levator veli palatini muscle from base of the skull (origin) through the midline of the muscle bundle to } \\
\text { the point where the muscle inserts into the body of the velum as seen from an oblique coronal image. This measure was } \\
\text { taken for the right and left muscle bundles and averaged for a mean value }\end{array}$ \\
\hline Intravelar length & $\begin{array}{l}\text { Distance }(\mathrm{mm}) \text { of the levator veli palatini muscle that is contained within the body of the velum. A single measure is } \\
\text { obtained that represents a portion of the left and right levator muscle bundles }\end{array}$ \\
\hline Velar insertion distance & $\begin{array}{l}\text { Distance }(\mathrm{mm}) \text { between the locations where the levator bundles insert into the body of the velum as seen on the midsagittal } \\
\text { image }\end{array}$ \\
\hline Palate length & Distance $(\mathrm{mm})$ from the anterior nasal spine to the posterior nasal spine as seen on the midsagittal image \\
\hline PNS-incisive foramen & Distance $(\mathrm{mm})$ between the posterior nasal spine and incisive foramen as seen on the midsagittal image \\
\hline PNS-PPW & Distance $(\mathrm{mm})$ between the posterior nasal spine and posterior pharyngeal wall as seen on the midsagittal image \\
\hline PNS-levator & $\begin{array}{l}\text { Linear distance }(\mathrm{mm}) \text { from the posterior nasal spine to the middle of the levator muscle sling where it inserts into the body } \\
\text { of the velum as seen on the midsagittal image }\end{array}$ \\
\hline Velar length & $\begin{array}{l}\text { Curvilinear line }(\mathrm{mm}) \text { drawn in the velar midline extending from the posterior nasal spine to the tip of the uvula as seen on } \\
\text { the midsagittal image }\end{array}$ \\
\hline Velar thickness & $\begin{array}{l}\text { Perpendicular distance }(\mathrm{mm}) \text { between the lines drawn tangent to the velar knee on the nasal side and the velar dimple on } \\
\text { the oral side from the midsagittal image }\end{array}$ \\
\hline Velar knee-PPW & Linear distance $(\mathrm{mm})$ from the velar knee to the posterior pharyngeal wall as seen on the midsagittal image \\
\hline VP ratio & $\begin{array}{l}\text { Velar length divided by pharyngeal depth. Pharyngeal depth refers to the distance from the posterior nasal spine and the } \\
\text { posterior pharyngeal wall at the level of velopharyngeal closure as seen on the midsagittal image }\end{array}$ \\
\hline
\end{tabular}




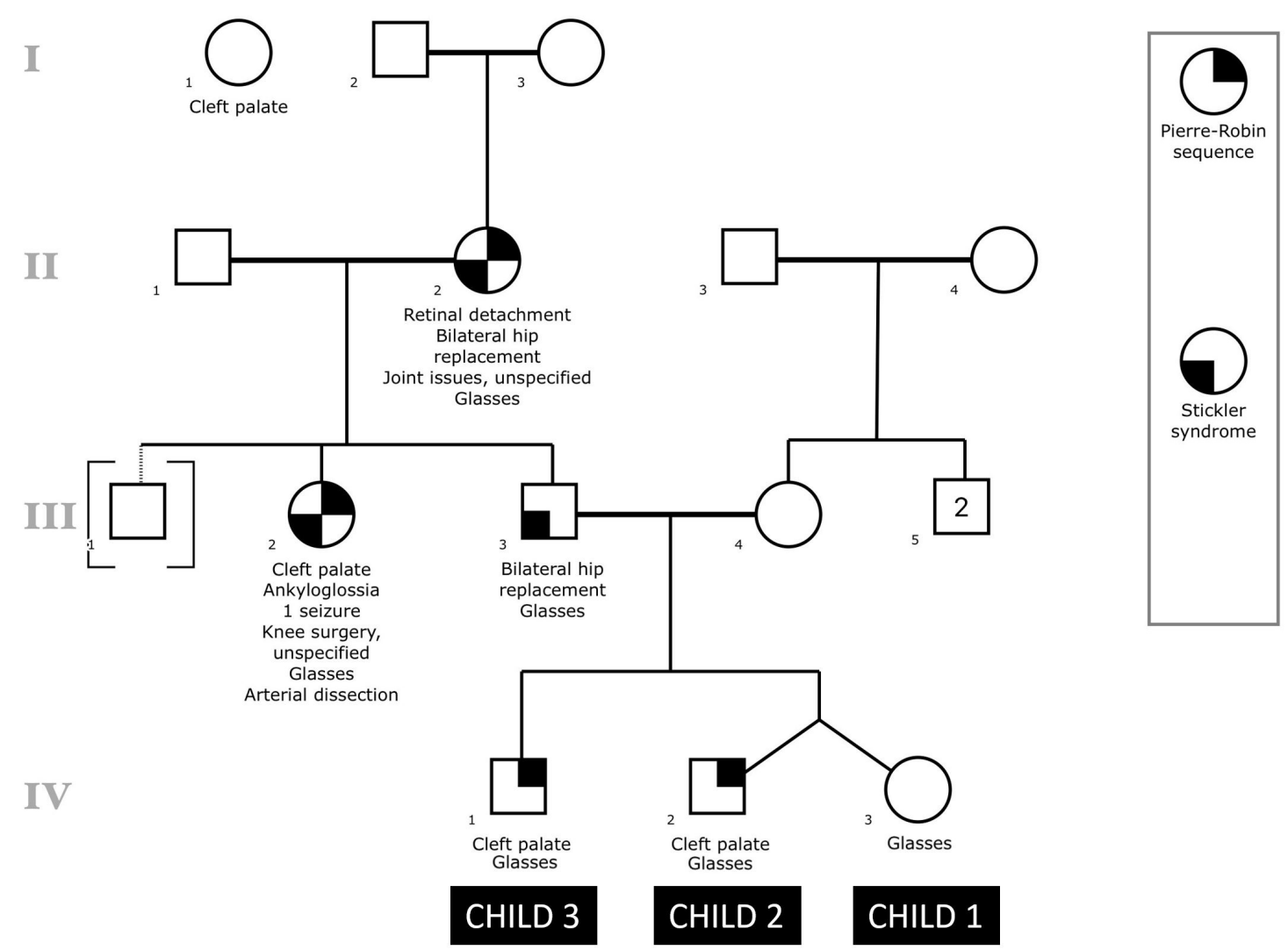

Figure 1. Pedigree of family history is shown with respect to the three children of interest in this study. All symbols follow standardized human pedigree nomenclature [47]. Squares represent males, and circles represent females. Relationship lines are interpreted as such: single horizontal lines demonstrate a partnership, vertical lines demonstrate a kinship, and vertical lines connected by horizontal line above individuals represent siblings. Fraternal twins are drawn as vertical lines connecting to one point on the horizontal sibling line. Solid lines represent biological relationships, whereas dotted lines are not biologically related.

als IV:1 and IV:2 have a history of PRS with cleft palate and glasses. Individual IV:3, fraternal twin sister of IV:2, has glasses but not PRS or cleft palate. Individual III:3, biological father to children in generation IV, has a clinical diagnosis of Stickler syndrome along with a history of bilateral hip replacement and glasses. Individual III:2, full sister of III:3, has a clinical diagnosis of Stickler syndrome along with a history of a cleft palate, PRS, ankyloglossia, glasses, one seizure, unspecified knee surgery, and an arterial dissection. Individual III:1 was adopted into the family. Individual II:2 has a clinical diagnosis of Stickler syndrome along with a history of PRS, retinal detachment, bilateral hip replacement, glasses, and other unspecified joint issues. There was also a reported aunt of individual III:3 with unknown relationship who had a history of cleft palate. Individual III:4, biological mother of individuals in generation IV, and other maternal relatives have negative histories for PRS and/or Stickler syndrome.

\section{Child 1}

Child 1 (Individual IV:3 in Figure 1) is a 6-year, 8-month old female fraternal twin presenting with normal anatomy, that is, without PRS or Stickler diagnosis. See Table 2 for details regarding surgical history and demographic information. Child 1 had articulation within normal limits and no history of speech therapy. Perceptual resonance rating indicated resonance within normal limits with no audible nasal air emission. SNAP-R picture stimulus items yielded the following mean nasalance values: Bilabials (11\%), Alveolars (14\%), Sibilants (14\%), Velars (19\%), and Nasals (55\%), which are within the normative ranges [27]. Pressure flow values for velopharyngeal stimuli papa $\left(0.006 \mathrm{~cm}^{2}\right)$ and hamper $\left(0.031 \mathrm{~cm}^{2}\right)$ were also within normal limits.

Magnetic resonance images from the midsagittal and oblique coronal image planes are shown for Child 1 in Figure $2 \mathrm{~A}$ and D. As evident in Figure 2D, the levator muscle is seen as a visible U-shaped muscular sling. All craniofacial mea- 
Table 2. Surgical history and demographic information is provided for all participants

\begin{tabular}{|c|c|c|c|c|c|c|c|}
\hline Child & Gender & Age (year) & Weight (kg) & Height (cm) & $\mathrm{BMI}$ & Diagnoses & Surgical history \\
\hline $1^{*}$ & Female & $6 ; 8$ & 32.2 & 130.8 & 18.8 & $\begin{array}{l}\text { Twin } \\
\text { Glasses }\end{array}$ & $\begin{array}{l}\text { PE tubes } \\
\text { Tonsillectomy }\end{array}$ \\
\hline 2 & Male & $6 ; 8$ & 20.6 & 124.5 & 13.3 & $\begin{array}{l}\text { Twin PRS } \\
\text { Cleft palate } \\
\text { FTT } \\
\text { Glasses }\end{array}$ & $\begin{array}{l}\text { Mandibular distraction } \\
\text { G-tube placement } \\
\text { PE tubes } \\
\text { Palatoplasty }\end{array}$ \\
\hline 3 & Male & $9 ; 3$ & 45.1 & 147.3 & 20.8 & $\begin{array}{l}\text { PRS } \\
\text { Cleft palate } \\
\text { Glasses }\end{array}$ & $\begin{array}{l}\text { PE tubes } \\
\text { Palatoplasty }\end{array}$ \\
\hline
\end{tabular}

*Denotes the noncleft participant.

BMI, body mass index; PRS, pierre robin sequence; FTT, failure to thrive; PE, pressure equalizing; G, gastronomy.
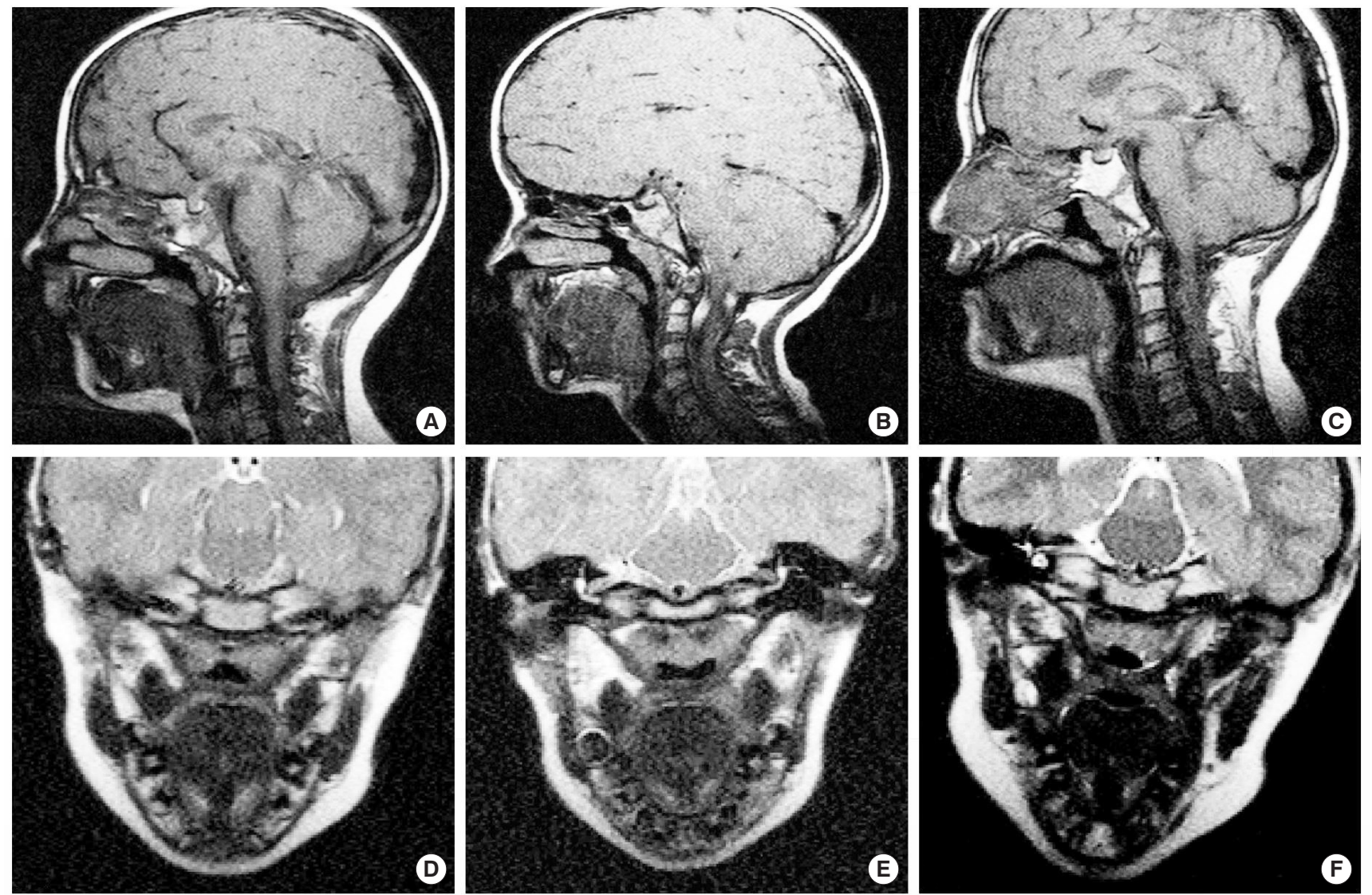

Figure 2. The top row shows the midsagittal magnetic resonance images for Child 1 (A), Child 2 (B), and Child 3(C). The bottom row shows magnetic resonance images from the oblique coronal plane for Child 1 (D), Child 2 (E), and Child 3 (F). From the oblique coronal plane, the levator veli palatini muscle can be seen as a dark U-shaped sling.

sures are within one standard deviation of the normative values for a Caucasian child of six years. See Table 3 for all MRI measurements and corresponding noncleft control measures by age, according to Perry et al. [40]. However, not all variables used in the present study have reported mean values for controls without cleft palate as evident by the empty cells for cer- tain variables in Table $3[40]$.

\section{Child 2}

Child 2 (Individual IV:2 in Figure 1) is a 6-year, 8-month old male fraternal twin with PRS and repaired cleft palate. See Table 2 for details regarding surgical history and demographic 
Table 3. Craniofacial and velopharyngeal measures for all participants are shown in the table along with normative values for children by same age and race, according to Perry et al, 2018 [40]

\begin{tabular}{|c|c|c|c|c|c|}
\hline & $\begin{array}{c}\text { Child } 1 \\
6 ; 8 \mathrm{yr}\end{array}$ & $\begin{array}{c}\text { Child } 2 \\
6 ; 8 \mathrm{yr} \\
\text { PRS/CPO }\end{array}$ & Control for 6 yr old ${ }^{a}$ & $\begin{array}{c}\text { Child } 3 \\
\text { 9;3 yr } \\
\text { PRS/CPO }\end{array}$ & Control for $9 \mathrm{yr}$ old \\
\hline \multicolumn{6}{|l|}{ Craniofacial measures } \\
\hline Nasion-sella turcica & 56.11 & 58.03 & $57.3(2.5)$ & $52.00^{*}$ & $61.9(3.4)$ \\
\hline Sella turcica-basion & 34.95 & $29.87^{*}$ & $33.05(2.2)$ & 41.55 & $39.1(3.1)$ \\
\hline Opithsion-basion & 40.75 & 46.32 & - & 33.44 & - \\
\hline NSB angle & 129.00 & $122.10^{*}$ & $127.7(6.0)$ & 131.80 & $127.4(6.4)$ \\
\hline SBO angle & 228.50 & 215.00 & - & 213.60 & - \\
\hline SN-Point B angle & 79.40 & 82.60 & - & 83.30 & - \\
\hline SN-Point $A$ angle & 89.00 & 85.10 & - & 89.20 & - \\
\hline Point A-N-Point B angle & 12.40 & 2.60 & - & 5.60 & - \\
\hline ANS-basion & 75.77 & 72.69 & - & 84.92 & - \\
\hline Facial height & 94.37 & 89.40 & $90.9(6.3)$ & 99.32 & $99.9(2.7)$ \\
\hline Cranial length & 179.24 & 180.68 & - & 176.22 & - \\
\hline Cranial width & 143.87 & 143.73 & - & 149.32 & - \\
\hline Cranial index & 80.27 & 79.55 & - & 84.73 & - \\
\hline \multicolumn{6}{|l|}{ Velopharyngeal measures } \\
\hline Origin-Origin & 56.39 & 50.34 & $55.2(5.9)$ & 53.06 & $52.8(4.3)$ \\
\hline Levator length & 38.35 & 34.93 & $37.4(3.7)$ & 38.25 & $40.2(2.7)$ \\
\hline Angle of origin & 52.85 & 52.80 & $55.4(5.4)$ & 53.25 & $52.1(3.5)$ \\
\hline Extravelar length & 53.17 & 45.51 & - & 54.50 & - \\
\hline Intravelar length & 23.64 & 24.81 & - & 22.40 & - \\
\hline Velar insertion distance & 26.48 & 21.90 & - & 11.96 & - \\
\hline Palate length & 39.27 & 35.53 & - & 37.81 & - \\
\hline PNS-incisive foramen & 30.49 & 24.66 & - & 24.54 & - \\
\hline PNS-PPW & 18.67 & 15.33 & $20.3(5.8)$ & 19.03 & $19.5(3.8)$ \\
\hline PNS-levator & 12.07 & $9.10^{*}$ & $12.4(1.5)$ & $7.04^{*}$ & $10.1(1.8)$ \\
\hline Velar length & 27.65 & 26.25 & $26.0(3.7)$ & 25.41 & $28.0(3.7)$ \\
\hline Velar thickness & 8.55 & 7.26 & $7.4(1.6)$ & 9.49 & $8.8(1.0)$ \\
\hline Velar knee-PPW & 5.50 & 5.49 & $6.3(2.7)$ & $5.59^{*}$ & $11.0(2.5)$ \\
\hline VP ratio & 1.48 & 1.71 & - & 1.34 & \\
\hline
\end{tabular}

aPerry et al. (2018) [40].

Not all variables within the present study have comparable mean values reported by Perry et al., 2018 [40], thus these cells are left blank. Control measures are italicized. All measures outside of one standard deviation of the mean for the control group are bold with*. All measures of interest are reported in millimeters $(\mathrm{mm})$ with exceptions including NSB angle $\left({ }^{\circ}\right)$, SBO angle $\left({ }^{\circ}\right)$, angle of origin $\left({ }^{\circ}\right)$, and index/ratio calculations.

NSB, nasion-sella turcica-basion; SBO, sella turcica-basion-opithsion; ANS, anterior nasal spine; PNS, posterior nasal spine; VP, velopharyngeal; PPW, posterior pharyngeal wall.

information. At the time of this evaluation, Child 2 had developmental articulation errors (gliding of /l, r/). He also had a history of speech therapy for remediation of compensatory articulation errors, including velar backing of /t, $\mathrm{d}, \mathrm{n} /$ and posterior nasal fricative substitution for all sibilant phonemes and blends. Perceptual resonance rating indicated a mixed resonance (mild hypernasality and mild hyponasality) with occasional turbulent nasal air emission present during connected speech. SNAP-R picture stimulus items yielded the following mean nasalance values: Bilabials (9\%), Alveolars (9\%), Sibilants (12\%), Velars (7\%), and Nasals (54\%), which are within normative range [27]. Pressure flow values for velopha- 
ryngeal stimuli papa $\left(0.007 \mathrm{~cm}^{2}\right)$ and hamper $\left(0.000 \mathrm{~cm}^{2}\right)$ were also within normal limits.

Magnetic resonance images from the midsagittal and oblique coronal image planes are shown for Child 2 in Figure 2 (B and E). For craniofacial measures, the sella turcica-basion length was more than two standard deviations under the normative control value for Child 2. Nasion to sella turcica distance, nasion-sella turcica-basion angle, and facial height were all within the mean and standard deviation for comparison children of the same age [40]. As previously mentioned, Child 1 and 2 are fraternal twins, however, differences of greater than $4 \mathrm{~mm}$ or degrees were noted for sella turcica-basion distance $(5.08 \mathrm{~mm})$, opithsion-basion distance (5.57 $\mathrm{mm})$, nasion-sella turcica-basion angle $\left(6.9^{\circ}\right)$, sella turcicabasion-opithsion angle $\left(13.5^{\circ}\right)$, Point A-N-Point B angle (9.8 ${ }^{\circ}$, and facial height $(4.97 \mathrm{~mm})$. The twin with PRS demonstrated smaller values for these dimensions. For all other craniofacial variables assessed, differences were within $3.90 \mathrm{~mm}$ or degrees between these two individuals. Comparison of the midsagittal images (Figure 2A-C) highlights the posterior displacement of the facial skeleton in Child 2. The oblique coronal image of Child 2 (Figure 2E) demonstrates a cohesive levator sling that appears to be of similar thickness to that of Child 1 , however, the length of the muscle is nearly $4 \mathrm{~mm}$ shorter than that of Child 1.

Compared to the mean and standard deviations for the noncleft control children of the same age [40], Child 2 displayed values that were smaller than the mean but still within one standard deviation for measures of origin-origin distance, levator length, angle of origin, posterior nasal spine-posterior pharyngeal wall distance, and velar knee to posterior pharyngeal wall distance. Velar thickness was greater than one standard deviation above the normative mean. The distance from the posterior hard palate to the insertion of the levator was smaller than the mean values observed in control noncleft participants [40]. This indicates the levator muscle is more anteriorly positioned in Child 2 compared to control participants of the same age. See Table 3 for all MRI measurements and corresponding noncleft control measures by age, according to Perry et al. [40].

\section{Child 3}

Child 3 (Individual IV:1 in Figure 1) is a 9-year, 3-month old male with PRS and repaired cleft palate. See Table 2 for details regarding surgical history and demographic information. Child 3 had articulation within normal limits and no history of speech therapy. Perceptual ratings indicated mild hyponasality with no audible nasal air emission. SNAP-R picture stimulus items yielded the following mean nasalance values: Bilabials (8\%), Alveolars (6\%), Sibilants (10\%), Velars (8\%), and Nasals (49\%), which are within normal limits [27]. Pressure flow values for velopharyngeal stimuli papa $\left(0.007 \mathrm{~cm}^{2}\right)$ and hamper $\left(0.002 \mathrm{~cm}^{2}\right)$ were also within normal limits.

Magnetic resonance images from the midsagittal and oblique coronal image planes are shown for Child 3 in Figure 2C and F. Nasion-sella turcia distance was the only craniofacial measure to be greater than two standard deviations below the mean. For velopharyngeal measures, levator length and the distance from the velar knee to the posterior pharyngeal wall were greater than two standard deviations below the normative mean. See Table 3 for all MRI measurements and corresponding noncleft control measures by age, according to Perry et al. [40].

\section{DISCUSSION}

Previous studies have quantified the facial skeletal morphology of children with nonsyndromic PRS. Children with PRS have a proportionate retrusion of the maxilla and mandible, which result in a convex facial profile. Shen et al. [24] reported no significant difference in maxillary and mandibular length for children 4-7 years of age with PRS compared to those with isolated cleft palate. However, the authors observed mandibular length to be significantly shorter among children 10-13 years of age [24]. Although measures in the present study were different from those of Shen et al. [24], this study did observe differences between Child 1 and 2 in the craniofacial skeleton. Specifically, decreased palate length, most notably from the posterior nasal spine to the incisive foramen, was greatly reduced for the two participants with PRS in the present case study. This suggests a retruded maxilla among those in the present study with a diagnosis of PRS, similar to previous findings [24].

Associated comorbidities can put syndromic patients with cleft palate at risk for poor speech outcomes [41]. Successful cleft repair in individuals with PRS has been reported using the von Langenbeck technique at 18 months of age, however, long-term speech outcomes were not reported [42]. Patel et al. [43] found a significantly higher incidence of velopharyngeal insufficiency following primary palatoplasty for syndromic (38\%) compared to nonsyndromic (16\%) PRS after reviewing 96 cases retrospectively. Of the syndromic cases, Stickler syn- 
drome was the most commonly associated condition (45\% of syndromic cases), with $25 \%$ of these patients developing velopharyngeal insufficiency [43]. It has been proposed that the maxillary hypoplasia in Stickler syndrome results in a smaller resting velopharyngeal gap, therefore explaining the lower incidence of velopharyngeal insufficiency compared to others with syndromic PRS [44]. Of interest in the present study, both children with a history of cleft palate (Child 2 and 3 ) showed a more anteriorly positioned levator sling compared to both the child without cleft palate and PRS diagnosis and also to noncleft control participants reported by Perry et al. [40]. In noncleft anatomy, the levator muscle inserts into the middle $40 \%$ of the velar length [45]. An anteriorly positioned levator muscle sling produces a velar eminence that yields an unfavorable function. To our knowledge, this is the first study to examine structure and positioning of the levator muscle in individuals with PRS and/or Sticker syndrome. Future research should employ a larger sample size to determine muscular positioning during palatoplasty and the corresponding relationship to speech outcomes within this population. Dynamic assessment of velopharyngeal closure during speech would be critical to better understand the causes of velopharyngeal dysfunction in one child (Child 2) compared to normal resonance found in Child 3.

Overall, there is very little information regarding speech outcomes of individuals with PRS with or without Sticker syndrome. A retrospective review of 32 patients with Stickler syndrome and 45 patients with PRS resulted in competent speech for $73.3 \%$ of patients with Stickler syndrome and $71.4 \%$ with associated PRS [41]. Although Child 2 and 3 in the present study both had PRS and repaired cleft palate, only Child 2 developed hypernasality and compensatory articulation errors. We were intrigued by the variability in speech outcomes between participants in this case study and anticipated anatomical differences may be present that would increase the likelihood that one participant would present with hypernasality and a history of compensatory articulation errors. Reduced palate length has been reported as a possible predictor of velopharyngeal dysfunction [46]. Compensatory articulation errors are known to develop as a result of velopharyngeal dysfunction. When compared to Child 3, average muscle length (specifically extravelar length), PNS-levator insertion, and pharyngeal depth were drastically reduced in Child 2. Child 2 also had a larger velopharyngeal ratio. Although one cannot draw conclusions from this data set, these dimensions warrant further investigation into whether these characteristics can predict speech deficits in participants with repaired cleft palate, such as compensatory articulation errors and hypernasality.

With a sample size of two participants with PRS and one familial comparison, conclusions cannot be drawn as to which craniofacial and velopharyngeal measures vary between participants with or without PRS. This study adds to the literature base regarding anatomical variables of individuals with PRS and indicates several areas that warrant further investigation with a larger sample size. To our knowledge, the present case study is the first to examine levator muscle variables in individuals with PRS. This is an important application of craniofacial and velopharyngeal measures to individuals with repaired cleft palate, specifically within syndromic populations. Future research in this area should quantify the variables included in this study within a greater sample size and compare to normative data to determine differences in anatomic parameters between these populations. Comparison between individuals with PRS and cleft palate only, such as that completed by Shen et al. [24], should be performed utilizing velopharyngeal variables to determine whether differences in skeletal morphology influence velopharyngeal variables for those with PRS.

\section{REFERENCES}

1. Carey JC, Fineman RM, Ziter FA. The Robin sequence as a consequence of malformation, dysplasia, and neuromuscular syndromes. J Pediatr. 1982;101:858-864.

2. Robin P. Glossoptosis due to atresia and hypotrophy of the mandible. Am J Dis Child. 1934;48:541-547.

3. Frohberg U, Lange RT. Surgical treatment of Robin sequence and sleep apnea syndrome: case report and review of the literature. J Oral Maxillofac Surg. 1993;51:1274-1277.

4. Evans AK, Rahbar R, Rogers GF, Mulliken JB, Volk MS. Robin sequence: a retrospective review of 115 patients. Int J pediatr Otorhinolaryngol. 2006;70:973-980.

5. Sesenna E, Magri AS, Magnani C, Brevi BC, Anghinoni ML. Mandibular distraction in neonates: indications, technique, results. Ital J Pediatr. 2012;38:7.

6. van den Elzen APM, Semmekrot BA, Bongers EMHF, Huygen PLM, Marres HAM. Diagnosis and treatment of the Pierre Robin sequence: results of a retrospective clinical study and review of the literature. Eur J Pediatr. 2001;160:47-53.

7. Printzlau A, Anderson M. Pierre robin sequence in Denmark: a retrospective population-based epidemiological study. Cleft Palate Craniofac J. 2004;41:47-52.

8. Stickler GB, Hughes W, Houchin P. Clinical features of hereditary progressive arthro-ophthalmopathy (Stickler syndrome): a survey. Genet Med. 2001;3:192-196. 
9. Soulier M, Sigaudy S, Chau C, Philip N. Prenatal diagnosis of Pierre-Robin sequence as part of Stickler syndrome. Prenat Diagn. 2002;22:567-568.

10. Liberfarb RM, Levy HP, Rose PS, et al. The Stickler syndrome: Genotype/phenotype correlation in 10 families with Stickler syndrome resulting from seven mutations in the type II collagen locus COL2A1. Genet Med. 2003;5:21-27.

11. Rose PS, Levy HP, Liberfarb RM, et al. Stickler syndrome: Clinical characteristics and diagnostic criteria. Am J Med Genet A. 2005; 138A:199-207.

12. Kollara L, Perry J. Effects of gravity on the velopharyngeal structures in children using upright magnetic resonance imaging. Cleft Palate-Cran J. 2014;51:669-676.

13. Tian W, Li Y, Yin H, Zhao SF, Li S, Wang Y, et al. Magnetic resonance imaging assessment of velopharyngeal motion in Chinese children after primary palatal repair. J Craniofac Surg. 2010;21: 578-587.

14. Tian W, Yin H, Li Y, Zhao S, Zheng Q, Shi B. Magnetic resonance imaging assessment of velopharyngeal structures in Chinese children after primary palatal repair. J Craniofac Surg. 2010b;21:568577.

15. Breugem CC, Evans KN, Poets CF, Suri S, Picard A, Filip C, et al. Best practices for the diagnosis and evaluation of infants with Robin sequence: a clinical consensus report. JAMA Pediatr. 2016; 170:894-902.

16. Figueroa AA, Glubker TJ, Fitz MG, BeGole, EA. Mandible, tongue, and airway in Pierre Robin sequence: a longitudinal cephalometric study. Cleft Palate Craniofac J. 1991;28:425-434.

17. Hermann NV, Kreiborg S, Darvann TA, Jensen BL, Dahl E, Bolund S. Craniofacial morphology and growth comparisons in children with Robin sequence, isolated cleft palate, and unilateral complete cleft lip and palate. Cleft Palate Craniofac J. 2003;40:373-396.

18. Hotz M, Gnoinski W. Clefts of the secondary palate associated with the "Pierre Robin Syndrome." Swed Dent J. 1982;6:89-98.

19. Krimmel M, Kluba S, Breidt M, Bacher M, Dietz K, Buelthoff H, et al. Three-dimensional assessment of facial development in children with Pierre Robin sequence. J Craniofac Surg. 2009;20:20552060.

20. Laitinen SH, Heliovaara A, Ranta RE. Craniofacial morphology in young adults with the Pierre Robin sequence and isolated cleft palate. Acta Odontol Scand. 1997;55:223-228.

21. Laitinen SH, Ranta RE. Cephalometric measurements in patients with Pierre Robin Sequence and isolated cleft palate. Scand J Plast Reconstr Surg Hand Surg. 1992;26:177-183.

22. Marcovic M. Growth changes in cases of mandibular micrognathia. Trans Eur Orthod Soc. 1972:133-145.

23. Salerno S, Gagliardo C, Vitabile S, Militells C, La Tona G, Giuffre M, et al. Semi-automatic volumetric segmentation of the upper airways in patients with Pierre Robin sequence. Neuroradiol J. 2014; 27:487-494.

24. Shen Y, Sun J, Li J, Ji T, Li M, Huang W, et al. Using computer simulation and stereomodel for accurate mandibular reconstruction with vascularized iliac crest flap. Oral Surg, Oral Med, Oral Pathol
Oral Radiol. 2012;114:175-182.

25. Vegter F, Hage JJ, Mulder JW. Pierre Robin syndrome: mandibular growth during the first year of life. Ann Plast Surg. 1999;42:154157.

26. Chapman KL, Baylis A, Trost-Cardamone J, Corclero KN, Dixon A, Dobbelsteyn C, et al. The americleft speech project: a training and reliability study. Cleft Palate Craniofac J. 2016;53:93-108.

27. Kummer AW. The MacKay-Kummer SNAP Test-R: simplified nasometric assessment procedures. Lincoln Park, NJ: Kay-Pentax; 2005.

28. Perry JL, Kuehn DP. Magnetic resonance imaging and computer reconstruction of the velopharyngeal mechanism. J Craniofac Surg. 2009;20:1739-1746.

29. Perry JL, Kuehn DP. Three-dimensional computer reconstruction of the levator veli palatini muscle in situ using magnetic resonance imaging. Cleft Palate Craniofac J. 2007;44:421-423.

30. Perry JL, Kuehn DP, Sutton BP, Gamage JK, Xiangming F. Anthropometric analysis of the velopharynx and related craniometrics dimensions in three adult populations using MRI. Cleft Palate Craniofac J. 2016;53:e1-e13.

31. Chung CS, Bixler D, Watanabe T, Koguchi H, Fogh-Anderson P. Segregation analysis of cleft lip with or without cleft palate: A comparison of Danish and Japanese data. Am J Hum Genet. 1986; 39:603-611.

32. Johannsdottir B, Thordarson A, Magnusson TE. Craniofacial skeletal and soft tissue morphology in Icelandic adults. Eur J Orthod. 2004;26:245-250.

33. Liu B, Jiang JW, Wilson BC, Du L, Yang SN, Wang JY, et al. Systematic infusion of naloxone reduces degeneration of rat substantia nigral dopaminergic neurons induced by intranigral injection of lipopolysaccharide. J Pharmacl Exp Ther. 2000;295:125-132.

34. Mahmud S. Cranial size and its relations to the length of the hard palate and retropalatal space in Japanese dry skulls. Shika Kiso Igakkai Zasshi. 1989;31;597-602.

35. Yeong P, Huggare J. Morphology of Singapore Chinese. Eur J Orthod. 2004;26:605-612.

36. Ettema SL, Kuehn DP, Perlman AL, Alperin N. Magnetic resonance imaging of the levator veli palatine muscle during speech. Cleft Palate Craniofac J. 2002;39:130-144.

37. Perry JL, Kuehn DP, Sutton BP. Morphology of the levator veli palatini muscle using magnetic resonance imaging. Cleft Palate Craniofac J. 2013;50:64-75.

38. Perry JL, Sutton BP, Kuehn DP, Gamage JK. Using MRI for assessing velopharyngeal structures and function. Cleft Palate Craniofacl J. 2014;51:476-485.

39. Tian W, Redett RJ. New velopharyngeal measurements at rest and during speech: implications and applications. J Craniofac Surg. 2009;20:532-539.

40. Perry JL, Kollara L, Kuehn DP, Sutton BP, Fang X. Examining sexual and racial dimorphism among a child population using magnetic resonance imaging. Cleft Palate Craniofac J. 2018;55:21-34.

41. Basta MN, Silvestre J, Stransky C, Solot C, Cohen M, McDonaldMcGinn D, et al. A 35-year experience with syndromic cleft palate 
repair: operative outcomes and long-term speech function. Ann Plast Surg. 2014;73:S130-S135.

42. Andrews S, Sam M, Krishnan R, Ramesh M, Kunjappan SM. Surgical management of a large cleft palate in a Pierre Robin sequence: a case report and review of literature. J Pharm Bioallied Sci. 2015;7:S718-S720.

43. Patel KB, Sullivan SR, Murthy AS, Marrinan E, Mulliken JB. Speech outcome after palatal repair in nonsyndromic versus syndromic Robin sequence. Plast Reconstr Surg. 2014;134:168.

44. Rogers GF, Lim AA, Mulliken JB, Padwa BL. Effect of a syndromic diagnosis on mandibular size and sagittal position in Robin sequence. J Oral Maxillofac Surg. 2009;67:2323-2331.
45. Boorman JG, Sommerlad BC. Levator palate and palatal dimples: their anatomy, relationship and clinical significance. Br J Plast Surg. 1985;38:326-332.

46. D’Antonio LL, Eichenberg BJ, Zimmerman GJ, Patel S, Riski JE, Herber SC, et al. Radiographic and aerodynamic measures of velopharyngeal anatomy and function following Furlow Z-plasty. Plast Reconstr Surg. 2000;106:539-549.

47. Bennett RL, French KS, Resta RG, Doyle DL. Standardized human pedigree nomenclature: update and assessment of the recommendations of the national society of genetic counselors. J Genet Couns. 2008;17:424-433. 